\title{
An assertive community treatment programme led to improved housing stability in homeless people with severe mental illness
}

\author{
Lehman AF, Dixon LB, Kernan E, et al. A randomized trial of assertive community treatment for homeless persons with severe \\ mental illness. Arch Gen Psychiatry 1997 Nov;54:1038-43.
}

\section{Objective}

To evaluate the effectiveness of an assertive community treatment (ACT) programme in homeless people with severe and persistent mental illnesses.

\section{Design}

Randomised controlled trial with 12 months of follow up.

\section{Setting}

Metropolitan Baltimore, Maryland, USA.

\section{Patients}

152 homeless people (mean age $39 \mathrm{y}, 89 \%$ men) with a history of current or recent homelessness and severe and persistent psychiatric disorder. Patients were recruited from inner city psychiatric hospitals or referred by city centre agencies serving homeless people.

\section{Intervention}

77 patients were allocated to an ACT programme (based on the Stein and Test model) and 75 to usual community services. The ACT team consisted of 12 full time equivalent staff including nurses, social workers, rehabilitation counsellors, consumer advocates, and a psychiatrist. Each patient in the ACT group was assigned to a mini team consisting of a clinical case manager, an attending psychiatrist, and a consumer advocate. Fidelity of the programme to the Stein and Test model was maintained throughout the trial. Subjects were paid US $\$ 40$ for baseline and $\$ 20$ for follow up assessments.

\section{Main outcome measures}

Days in community housing, days in psychiatric hospital, uptake of outpatient care, quality of life (Lehman Quality-of-Life Interview), psychiatric symptoms (Colorado Symptom Index), and patient perceived health status (Medical Outcome Study 36-Item Short Form Health Survey).

\section{Main results}

During 12 months of follow up, patients in the ACT group had more days in stable community housing $(\mathrm{p}=0.006)$ (table). They also spent fewer days in psychiatric hospital $(\mathrm{p}=0.01)$ (table). There was an increase in the uptake of outpatient care in the ACT group $(p<0.001)$. Overall, the treatment and control groups did not differ for quality of life, psychiatric symptoms, or health status.

\section{Conclusion}

An assertive community treatment programme led to more stable housing and greater uptake of outpatient services in homeless people with severe and persistent psychiatric illnesses.

Assertive community treatment (ACT) programme v usual community services*

\begin{tabular}{llll}
\hline $\begin{array}{l}\text { Outcomes over 12 } \\
\text { months }\end{array}$ & $\begin{array}{l}\text { ACT adjusted } \\
\text { mean }\end{array}$ & $\begin{array}{l}\text { Usual services } \\
\text { adjusted mean }\end{array}$ & $\begin{array}{l}\text { Adjusted mean difference } \\
(95 \% \text { CI })\end{array}$ \\
\hline $\begin{array}{l}\text { Days in community } \\
\text { housing }\end{array}$ & 210.2 & 160.1 & $\begin{array}{l}50.1 \\
(15.5 \text { to } 84.7)\end{array}$ \\
$\begin{array}{l}\text { Inpatient days } \\
\text { (n) }\end{array}$ & 35.4 & 66.9 & $\begin{array}{l}-31.5 \\
(-56.1 \text { to }-6.9)\end{array}$ \\
\hline
\end{tabular}

$* \mathrm{CI}=$ confidence interval; numbers calculated from data in article.

Source of funding: University of Maryland. For article reprint: Dr A F Lehman, Department of Psychiatry, University of Maryland, Center for
Mental Health Sciences, 685 W Baltimore Street, MSTF Suite 300, Baltimore, MD 21201-1549, USA. Fax +14107062490.

\section{Commentary}

ACT is an intensive and expensive approach to caring for severely mentally ill people in the community. Unlike other forms of "case management", ACT is practised according to a highly specified model. Key features of the model include: (a) assertively maintaining contact with patients; (b) providing intensive multidisciplinary care "in vivo"; and (c) 24 hour availability of care. ${ }^{1}$ ACT is designed for patients who are difficult to engage in treatment, and there are few groups that fit this description better than homeless people with severe mental illness.

This trial by Lehman et al is not the first successful trial comparing ACT with standard care in the homeless (Morse et al showed that ACT reduced the number of days spent homeless ${ }^{2}$ ), but it has 2 advantages over previous work. Firstly, the researchers achieved an extremely good follow up rate ( $83 \%$ at 12 months), and secondly, they made strong efforts to stick to the ACT model.

This trial has now clearly established ACT (when properly practised) as an effective strategy for achieving housing stability in severely mentally ill homeless people and to engage them in care. This is a major achievement. The trial has not, however, established that ACT has a major effect on symptoms, quality of life, or health status in this population (although some promising post hoc comparisons are reported).

These findings raise the interesting question of how much society is prepared to pay to stabilise and engage homeless mentally ill people. ACT usually performs well in economic analyses because it reduces the use of expensive hospital care in patients who were previously high users of hospital care. In this trial, however, interpretation of the results regarding hospital use should be cautious because the data appear skewed. ACT may prove an expensive intervention for the homeless mentally ill, because they are low users of hospital care. The economic analysis promised by these authors will be awaited with interest.

Max Marshall, MD University of Manchester Lancashire, UK

1 McGrew JH, Bond GR. Critical ingredients of assertive community treatment: judgments of
the experts. J Ment Health Adm 1995;22:113-25.

2 Morse GA, Calsyn RJ, Allen G, et al. Experimental comparison of the effects of three treatment programs for homeless mentally ill people. Hosp Community Psychiatry 1992;43:
1005-10. 